\title{
Secondary endoscopic submucosal dissection for residual or recurrent tumors after gastric endoscopic submucosal dissection
}

\author{
Shu Hoteya $\cdot$ Toshiro Iizuka $\cdot$ Daisuke Kikuchi $\cdot$ Toshifumi Mitani · \\ Akira Matsui - Osamu Ogawa · Tsukasa Furuhata - Satoshi Yamashta • \\ Akihiro Yamada $\cdot$ Mitsuru Kaise $\cdot$ Naohisa Yahagi
}

Received: 6 September 2013/Accepted: 24 November 2013/Published online: 6 December 2013

(c) The International Gastric Cancer Association and The Japanese Gastric Cancer Association 2013

\begin{abstract}
Background Endoscopic submucosal dissection (ESD) is a widely accepted technique for the management of gastric tumors. However, residual or recurrent tumors can occur after ESD; currently, there is no adequate management strategy for these tumors. Thus, the aim of the present study was to establish a strategy of secondary ESD (sESD) for cases with positive lateral margins $(\mathrm{LM}+)$, which cause post-ESD residual or recurrent tumors.

Methods Fifty-three lesions that were subjected to ESD were diagnosed as $\mathrm{LM}+$ with suspected local residual tumor. The short- and long-term outcomes of early sESD (performed shortly after the initial ESD in LM+ cases to prevent local recurrence) were retrospectively compared with those of late SESD (performed after the detection of recurrent tumors).

Results Of the $53 \mathrm{LM}+$ cases, the local residual positive rate was $38.5 \%(10 / 26)$ in those undergoing early SESD or additional surgery and the local recurrence rate was $29.6 \%$ $(8 / 27)$ in those that were not treated. Thus, the overall incidence of residual or recurrent tumors in $\mathrm{LM}+$ cases was $34.0 \%$ (18/53). Both early and late sESD had favorable outcomes with no severe complications: $100 \%$ of early SESD resections were curative, compared with $86.7 \%$ of late sESD resections, over the course of a mean $( \pm \mathrm{SD})$ observation period of $50.8 \pm 16.7$ months. The
\end{abstract}

S. Hoteya $(\bowtie) \cdot$ T. Iizuka · D. Kikuchi · T. Mitani .

A. Matsui - O. Ogawa $\cdot$ T. Furuhata - S. Yamashta

A. Yamada - M. Kaise $\cdot$ N. Yahagi

Department of Gastroenterology, Toranomon Hospital,

2-2-2 Toranomon, Minato-ku, Tokyo 105-8470, Japan

e-mail: torashu@hotmail.com

N. Yahagi

Cancer Center, Keio University, Tokyo, Japan performance of early SESD was significantly greater than that of late sESD (in terms of dissection speed).

Conclusions Early sESD is more reliable than late sESD as a therapeutic strategy for salvaging residual tumors and for preventing recurrence. However, if a tumor has already recurred, late sESD remains useful.

Keywords ESD - Gastric tumor - Residual or recurrent tumors · Secondary ESD $\cdot$ Long-term outcomes

\section{Introduction}

Endoscopic submucosal dissection (ESD) was developed to resect early gastric neoplasms that could not be resected by conventional endoscopic mucosal resection (EMR): i.e., those with a large size, irregular shape, coexisting ulcer findings, or a difficult location [1-5].

Therapies involving ESD have a higher rate of complete resection (R0) and lower rate of local recurrence than conventional EMR [6-11]. However, the fact that ESD is carried out for difficult-to-resect tumors has caused the new, though infrequent, problem of post-ESD local residual or recurrent tumors, the characteristics of which are poorly understood. Furthermore, appropriate strategies for the management of patients with incomplete resection in the lateral margin after ESD have not been established. Secondary ESD (sESD) is used to resect post-ESD recurrent tumors, but the severe and extensive fibrosis present in the submucosal layer as a result of the initial ESD, means that the technical difficulty of the procedure is very high, and both the patient's safety and likelihood of being cured by the procedure must be assessed. It is clearly important to prevent recurrent tumors and we previously reported the feasibility of early sESD [i.e., sESD implemented shortly 
after the initial ESD to prevent local recurrence in lateral margin positive (LM+) cases] [12]. Here, we compared cases of early sESD to cases of late sESD (i.e., sESD performed when local recurrence is histologically proven during follow-up). In early sESD, the ESD ulcer is still open and there is no scar formation, whereas in late sESD, the ulcer has formed a significant scar.

The aim of the present study was to compare outcomes between early and late SESD to establish an appropriate treatment strategy for patients with LM+ tumors after the initial ESD. To this end, we evaluated the clinical outcomes of post-ESD residual or recurrent tumors.

\section{Patients and methods}

\section{Patients}

A total of 2042 superficial gastric neoplasms in 1593 consecutive patients who underwent ESD at Toranomon Hospital, Tokyo, Japan between April 2005 and March 2013 were enrolled in the study. We evaluated cases with positive lateral margins (LM+), which may cause postESD residual or recurrent tumors. Pretreatment indications and curative criteria listed in the Japanese gastric cancer treatment guidelines were as follows: (1) nonulcerated, differentiated intramucosal cancers, regardless of tumor size; (2) ulcerated, differentiated intramucosal cancers $<30 \mathrm{~mm}$; (3) differentiated minute submucosal cancers (SM1; $<500 \mu \mathrm{m})<30 \mathrm{~mm}$; (4) nonulcerated, undifferentiated intramucosal cancers $<20 \mathrm{~mm}$ [13].

The present case-series study protocol was approved by the medical ethics committee of Toranomon Hospital. All patients provided written informed consent for the proposed procedure and traditional treatments (i.e., conventional EMR or gastrectomy) were offered as options prior to treatment. Follow-up endoscopic examinations were performed after 2 and 6 months, and then every 12 months. Abdominal computed tomography or ultrasonography was performed annually or more frequently to identify lymph node and distant metastases.

\section{ESD procedure}

The initial ESD procedure was performed by using a dual knife, flex knife, or hook knife (KD-650, KD-630L, KD620 , respectively; Olympus Optical), or a combination of the above, as previously reported $[3,10]$.

The resected specimen was cut into 2-mm-thick slices after formalin fixation. The histological type, size, depth of invasion, lateral and vertical margins, and lymphatic-vascular invasion were evaluated in each slice according to the Japanese Classification of Gastric Carcinoma [14]. In the present study, the criteria for declaring $\mathrm{R} 0$ resection were en bloc resection with lateral and vertical margins free from tumor. Incomplete resection was defined as piecemeal resection or resection resulting in a histologically positive specimen margin ( $\mathrm{R} 1$ resection).

\section{Management after initial ESD}

In the present study, early SESD was defined as the procedure performed immediately after histological confirmation of positive lateral margins of the primary ESD specimen. Therefore, at the time early sESD is performed, the ESD ulcer is not scarred and is still open. "Late" sESD was defined as the procedure performed when local recurrence had been proven histologically during the follow-up period. At this time, the ESD ulcer has formed a scar. The procedures for both early and late sESD were the same as the initial ESD, with the exception that hyaluronic acid solution (MucoUp; Johnson \& Johnson Co. Ltd, Tokyo, Japan) was added to the injection solution when mucosal elevation was insufficient due to ulceration of the tumor or massive fibrosis of the submucosal layer caused by the initial ESD [15].

We determined the treatment for $\mathrm{LM}+$ after initial ESD according to the possibility of lymph node metastasis. Although the initial ESD was LM+, early SESD was performed when the resected specimen met the expanded criteria for curative resection listed in the Japanese gastric cancer treatment guidelines [13] and when the surgeon judged that the possibility of local residual tumor was high. However, in most cases of early SESD, the residual cancer could not be clearly recognized. Thus, the resection area for early sESD was determined on the basis of the number of LM+ slices and the shape of the cancer identified on the initial ESD specimen and from additional biopsies, if necessary.

Additional gastrectomy was performed in cases of noncurative resection with the possibility of lymph node metastasis as per the Japanese gastric cancer treatment guidelines [13]. Otherwise, patients were subjected to routine follow-up (including patient refusal of additional treatment).

Evaluations and analyses

We assessed the features of specimens that were LM+ after the initial ESD and the characteristics of residual or recurrent tumors (size, location, macroscopic findings and histology) according to the Japanese Classification of Gastric Carcinoma [14]. We also calculated the rates of local residual or recurrent tumors in $\mathrm{LM}+$ cases and the total local recurrence rate, and estimated the cumulative incidence of local recurrence by the Kaplan-Meier method. 
To verify the technical feasibility of curative ESD, the short-term results (tumor size, invasion depth, resection size, operation time, dissection speed, incidence of intraoperative excessive bleeding, incidence of postoperative bleeding, and perforation rate) and long-term results (local recurrence rate and distant metastasis rate) were retrospectively compared between early and late sESD. Data are presented as mean \pm SD. Statistical analysis was performed using the Chi-square test, Fisher's exact test, and Student's $t$ test. $P$ values $<0.05$ were considered statistically significant. All statistical analyses were performed using SPSS version 20 (SPSS IBM statistics).

\section{Results}

Among the 2042 superficial gastric neoplasms, R0 resection was achieved for 1955 tumors (95.7 \%), and 53 tumors were determined to be post-ESD LM+, with suspected local residual tumor. The clinicopathological characteristics of the 53 post-ESD LM+ tumors are listed in Table 1, and the flow diagram of the treatments is shown in Fig. 1.

Of the $53 \mathrm{LM}+$ tumors, 11 underwent early sESD and 15 underwent additional surgery shortly after the initial ESD; $38.5 \%(10 / 26)$ of the cases that underwent the above early treatments had local residual tumors. A total of 27 tumors did not undergo early sESD or additional gastrectomy; in follow-up, $29.6 \%(8 / 27)$ of these had local recurrence (mean time to recurrence, 26.9 months); most recurrences were discovered within 3 years of the initial ESD (Fig. 2). Of the 8 recurrent tumors, 2 underwent gastrectomy, 1 underwent tumor ablation by argon plasma coagulation (APC), and 5 underwent late sESD. From another hospital, we included an additional 10 recurrent tumors that underwent late sESD (not shown in Fig. 1), so the total number of recurrent tumors that underwent late sESD was 15 .

The patient characteristics and clinical features of early and late sESD are summarized in Table 2. The mean interval between initial ESD and SESD was 9 days for early sESD and 685 days for late sESD.

Table 3 shows the comparative outcomes for early and late sESD. The mean tumor resection area and operation time were not significantly different between early sESD $\left(19.3 \mathrm{~cm}^{2}\right.$ and $141.6 \mathrm{~min}$, respectively) and late sESD $\left(10.3 \mathrm{~cm}^{2}\right.$ and $126.3 \mathrm{~min}$, respectively). However, early and late sESD were significantly different in terms of dissection speed (13.5 vs. $8.7 \mathrm{~mm}^{2} / \mathrm{min}$, respectively). The complication rate (i.e., incidence of intraoperative excessive bleeding, postoperative bleeding, or perforation) was not significantly different between early and late sESD.

Specimens from the early sESD were combined with the corresponding specimens from the initial ESD, and the curability was evaluated by pathological diagnosis of the
Table 1 Clinicopathological characteristics of 53 lateral margin positive tumors after initial ESD

\begin{tabular}{|c|c|}
\hline Sex (male/female) & $44 / 9$ \\
\hline Age, mean \pm SD (years) & $67.8 \pm 11.8$ \\
\hline Age, range (years) & $35-87$ \\
\hline Tumor size, mean $\pm \mathrm{SD}(\mathrm{mm})$ & $24.5 \pm 14.1$ \\
\hline Tumor size, range $(\mathrm{mm})$ & $1-54$ \\
\hline Resected specimen size, mean \pm SD $(\mathrm{mm})$ & $45.2 \pm 16.3$ \\
\hline Resected specimen size, range $(\mathrm{mm})$ & $18-94$ \\
\hline \multicolumn{2}{|l|}{ Tumor location $[\%(n)]$} \\
\hline $\mathrm{U}$ & $26.4(14 / 53)$ \\
\hline M & $30.2(16 / 53)$ \\
\hline $\mathrm{L}$ & $35.8(19 / 53)$ \\
\hline Remnant stomach & $7.5(4 / 53)$ \\
\hline \multicolumn{2}{|l|}{ Macroscopic findings $[\%(n)]$} \\
\hline Protruded/elevated & $22.6(12 / 53)$ \\
\hline Flat/depressed & $64.2(34 / 53)$ \\
\hline Mixed & $13.2(7 / 53)$ \\
\hline \multicolumn{2}{|l|}{ Tumor depth $[\%(n)]$} \\
\hline $\mathrm{pM}$ & $83.0(44 / 53)$ \\
\hline pSM & $17.0(9 / 53)$ \\
\hline \multicolumn{2}{|l|}{ Histology $[\%(n)]$} \\
\hline Well differentiated & $56.6(30 / 53)$ \\
\hline Moderately differentiated & $32.0(17 / 53)$ \\
\hline Undifferentiated & $5.7(3 / 53)$ \\
\hline Adenoma & $5.7(3 / 53)$ \\
\hline Observation period, mean $\pm \mathrm{SD}$ (months) & $50.8 \pm 16.7$ \\
\hline Residual or recurrence rate of $\mathrm{LM}+$ cases $[\%(n)]$ & $34.0(18 / 53)$ \\
\hline Residual positive rate after additional therapy $[\%(n)]$ & $38.5(10 / 26)$ \\
\hline Local recurrence rate of follow-up cases $[\%(n)]$ & $29.6(8 / 27)$ \\
\hline Total local recurrence rate $[\%(n)]$ & $0.4(8 / 2042)$ \\
\hline
\end{tabular}

$L M+$ positive lateral margin, $E S D$ endoscopic submucosal dissection, $U$ upper one-third of the stomach, $M$ middle one-third of the stomach, $L$ lower one-third of the stomach, $p M$ intramucosal invasion, $p S M$ submucosal invasion

total reconstructed region. The curability of late SESD was determined according to the expanded indications for curative resection listed in the Japanese gastric cancer treatment guidelines [13].

Although $100 \%(11 / 11)$ of the early sESD resections were curative, $86.7 \%(13 / 15)$ of the late sESD resections were curative. Of the two non-curative late sESD resections, one case had post-ESD recurrences, resulting in massive submucosal invasion, and the other was diagnosed as $\mathrm{LM}+$ but no additional treatment was implemented. In patients for whom the resection was determined to be curative, there was no evidence of local recurrence or distant metastasis during a mean $( \pm S D)$ observation period of $39.2 \pm 25.8$ months (range 5.8-91.2 months) in the case of early sESD and $33.3 \pm 30.1$ months (range 11.9-80.6 months) in the case of late sESD. 
Fig. 1 Flow diagram of the lateral margin positive cases after initial ESD. $R 0$ resection en bloc resection with lateral and vertical margins free from cancer, $R 1$ resection piecemeal resection, or resection resulting in a histologically positive specimen margin, $L M+$ lateral margin positive, $V M+$ vertical margin positive, $s E S D$ secondary ESD, $A P C$ argon plasma coagulation

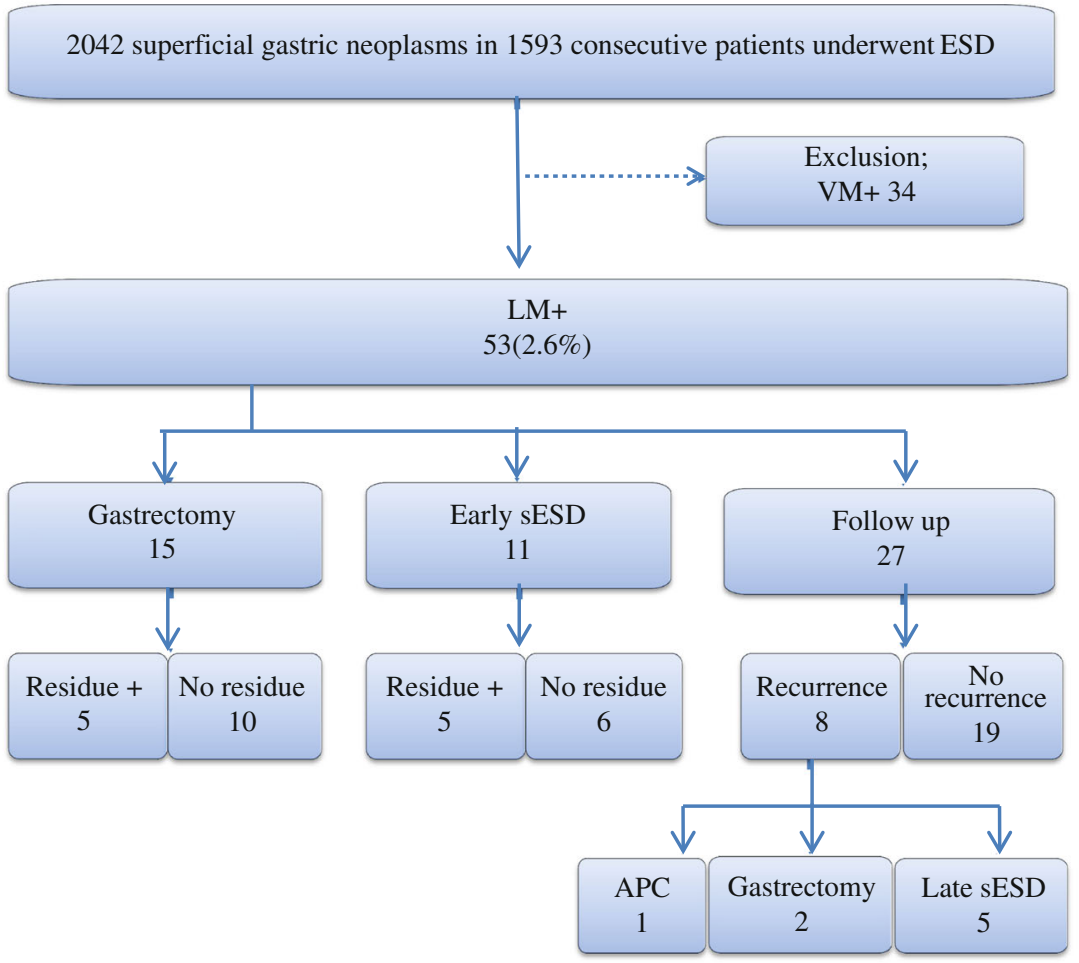

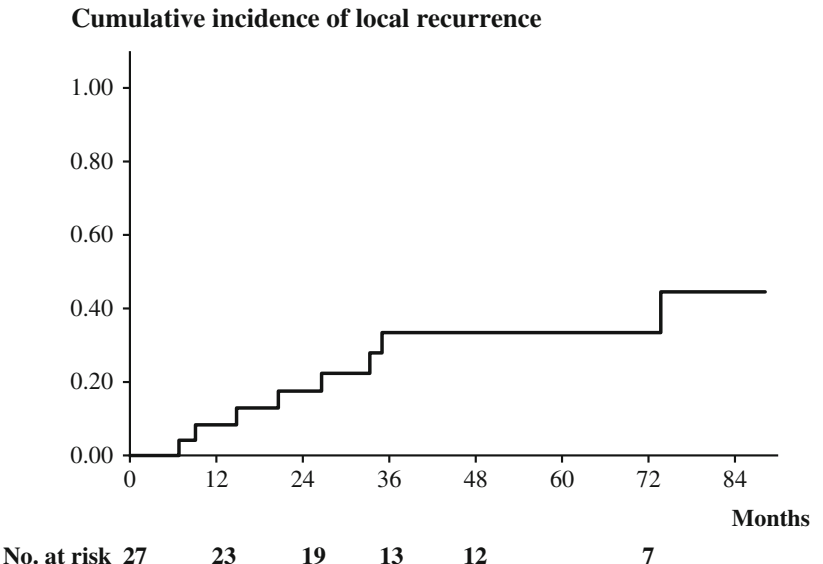

Fig. 2 Local recurrence in lateral margin positive cases subjected to no further treatment $(n=27)$

\section{Discussion}

Previous studies, each with several hundred cases, have reported the post-ESD local recurrence rate as $0-5.1 \%$ $[10,16-24]$, but there have been few detailed reports describing the clinical course of post-ESD recurrent tumors $[25,26]$. Here, we analyzed more cases over a longer observation period compared with previous studies, and the total local recurrence rate was $0.4 \%(8 / 2042)$. We demonstrated that the majority of post-ESD local recurrent tumors were detected within 3 years of the initial ESD. Further detailed analysis of 53 tumors that tested LM+
Table 2 Clinical characteristics of early sESD and late sESD

\begin{tabular}{lll}
\hline & Early sESD & Late sESD \\
\hline Tumor $(n)$ & 11 & 15 \\
Sex (male/female) & $8 / 3$ & $14 / 1$ \\
Age, mean \pm SD (years) & $63.9 \pm 11.6$ & $74 \pm 9.0$ \\
Tumor location [\% $(n)]$ & & \\
U & $18.2(2 / 11)$ & $40.0(6 / 15)$ \\
M & $54.5(6 / 11)$ & $33.3(5 / 15)$ \\
L & $27.3(3 / 11)$ & $26.7(4 / 15)$ \\
Macroscopic findings [\% $(n)]$ & & \\
Protruded or elevated & $0(0 / 11)$ & $26.7(4 / 15)$ \\
Flat or depressed & $45.5(5 / 11)$ & $73.3(11 / 15)$ \\
$\quad$ Not recognized & $54.5(6 / 11)$ & $0(0 / 15)$ \\
Interval after initial ESD, & $9 \pm 3$ & $685 \pm 501$ \\
mean \pm SD (days) & & \\
\hline
\end{tabular}

$E S D$ endoscopic submucosal dissection, $s E S D$ secondary ESD, $U$ upper one-third of the stomach, $M$ middle one-third of the stomach, $L$ lower one-third of the stomach

after the initial ESD, showed that the rate of occurrence of local residual tumors determined by early sESD or additional surgery was $38.5 \%(10 / 26)$, and the rate of local recurrence during follow-up was $29.6 \%(8 / 27)$, so the rate of residual or recurrent tumors was $34.0 \%$ (18/53) in total. These high rates strongly suggest that cases that are postESD LM+ require prompt additional treatment, and a treatment strategy to manage residual tumors and prevent recurrent tumors must be established. 
Table 3 Comparative outcomes of early and late sESD

\begin{tabular}{llll}
\hline & Early sESD & Late sESD & $P$ value \\
\hline Tumor $(n)$ & 11 & 15 & \\
$\begin{array}{l}\text { Resection area, } \\
\text { mean } \pm \text { SD }\left(\mathrm{cm}^{2}\right)\end{array}$ & $19.3 \pm 20.8$ & $10.3 \pm 5.3$ & $0.095^{\mathrm{a}}$ \\
$\begin{array}{l}\text { Operation time, } \\
\quad \text { mean } \pm \text { SD (min) }\end{array}$ & $141.6 \pm 104.3$ & $126.3 \pm 47.1$ & $0.328^{\mathrm{a}}$ \\
$\begin{array}{l}\text { Dissection speed, } \\
\text { mean } \pm \text { SD }\left(\mathrm{mm}^{2} / \mathrm{min}\right)\end{array}$ & $13.5 \pm 6.9$ & $8.7 \pm 4.6$ & $0.021^{\mathrm{a}}$ \\
$\begin{array}{l}\text { Intraoperative excessive } \\
\text { bleeding }(n)\end{array}$ & 0 & 0 & \\
$\begin{array}{l}\text { Postoperative bleeding }(n) \\
\text { Perforation rate }(n)\end{array}$ & 0 & 0 & \\
$\begin{array}{l}\text { Pathological tumor depth }(n) \\
\quad \text { No tumor or pM/pSM }\end{array}$ & $11 / 0$ & 0 & \\
$\begin{array}{l}\text { Curative/non-curative } \\
\text { resection }(n)\end{array}$ & $11 / 0$ & $12 / 3$ & $0.175^{\mathrm{b}}$ \\
$\begin{array}{l}\text { Observation from initial } \\
\quad \text { ESD, mean } \pm \mathrm{SD} \\
\quad(\text { months })\end{array}$ & $39.2 \pm 25.8$ & $33.3 \pm 30.1$ & $0.301^{\mathrm{a}}$ \\
$\begin{array}{l}\text { Regional recurrence }(n) \\
\text { Distant metastasis }(n)\end{array}$ & 0 & & \\
\hline
\end{tabular}

$E S D$ endoscopic submucosal dissection, $s E S D$ secondary ESD, $p M$ intramucosal invasion, $p S M$ submucosal invasion

a Student's $t$ test

b Fisher's exact test

There have been two published case reports of the feasibility and efficacy of early sESD: both our report [12] and that of Bae et al. [27] showed consistent findings. Here, with a larger number of cases and a longer observation period, we confirmed the feasibility, safety, and favorable long-term prognosis of early sESD. The results demonstrated that, when the resected specimen is oriented precisely by pathological evaluation immediately after the initial ESD, it is possible to map the location of the remnant tumor accurately and perform early SESD at the correct site.

Local recurrent gastric neoplasms that occur due to piecemeal resection or LM+ status after EMR are generally discovered as intramucosal neoplasms during followup care, and in many cases, clinical rescue is possible through endoscopic treatment, including late sESD [28, 29]; however, to the best of our knowledge, there has been only one case study reporting the efficacy of late SESD for post-ESD recurrent tumors [30]. Despite the technical difficulty of dissecting the submucosal layer correctly when there is rigid scar formation after the initial ESD, the results of the present study confirmed the feasibility and curability of late SESD, and the lack of severe complications, agreeing with previous findings [30].

ESD is minimally invasive and curative even for postESD recurrent tumors. However, radical surgery, which results in decreased quality of life, is necessary for some patients with progressive disease who did not receive appropriate follow-up care. Therefore, prevention of postESD recurrence is most important.

To the best of our knowledge, there have been no reports comparing the efficacy of sESD and late sESD. Here, we demonstrated that, while early SESD and late SESD were not significantly different in terms of resection area, overall operation times, or incidence of complications, early sESD showed significantly higher performance in terms of dissection speed. From the viewpoint of curability, early sESD was mostly performed for local residual tumors, whereas late SESD was sometimes performed for submucosal invasive cancer; therefore, although $100 \%$ of the early SESD resections were curative, $86.7 \%$ of the late SESD resections were curative. These results indicate that early SESD is the more reliable and feasible procedure as a therapeutic strategy for lesions that are $\mathrm{LM}+$ after the initial ESD to salvage residual tumors and to prevent recurrence.

Although this study was limited by its retrospective study design, we were able to assess a large number of consecutive case series in a single, high-volume center to establish the best methods for prevention and management of post-ESD recurrence. Taken together, the results indicated that both early and late sESD had favorable shortterm and long-term results. Since about $34 \%$ of tumors that tested LM+ after ESD developed local residual or recurrent disease, implementing early SESD as soon as possible, before complete scarring of the ulcer, is useful for salvaging residual tumors and preventing recurrence. If tumor recurrence occurs, late sESD of the tumor is useful.

\section{References}

1. Ohkuwa M, Hosokawa K, Boku N, Ohtu A, Tajiri H, Yoshida S. New endoscopic treatment for intramucosal gastric tumors using an insulated-tip diathermic knife. Endoscopy. 2001;33:221-6.

2. Yamamoto H, Sekine Y, Higashizawa T, Kihira K, Kaneko Y, Hosoya Y, et al. Successful en bloc resection of a large superficial gastric cancer by using sodium hyaluronate and electrocautery incision forceps. Gastrointest Endosc. 2001;54:629-32.

3. Yahagi N, Fujishiro M, Kakushima N, Omata M. Endoscopic submucosal dissection for early gastric cancer using the tip of an electrosurgical snare (thin type). Dig Endosc. 2004;16:34-8.

4. Gotoda T. A large endoscopic resection by endoscopic submucosal dissection procedure for early gastric cancer. Clin Gastroenterol Hepatol. 2005;3:S71-3.

5. Ono H. Endoscopic submucosal dissection for early gastric cancer. Chin J Dig Dis. 2005;6:119-21.

6. Oka S, Tanaka S, Kaneko I, Mouri R, Hirata M, Kawamura T, et al. Advantage of endoscopic submucosal dissection compared with EMR for early gastric cancer. Gastrointest Endosc. 2006;64:877-83.

7. Watanabe K, Ogata S, Kawazoe S, Koyama T, Kajiwara T, Shimoda Y, et al. Clinical outcomes of EMR for gastric tumors: 
historical pilot evaluation between endoscopic submucosal dissection and conventional mucosal resection. Gastrointest Endosc. 2006;63:776-82.

8. Shimura T, Sasaki M, Kataoka H, Tanida S, Oshima T, Ogasawara $\mathrm{N}$, et al. Advantages of endoscopic submucosal dissection over conventional endoscopic mucosal resection. J Gastroenterol Hepatol. 2007;22:821-6.

9. Chung IK, Lee JH, Lee SH, Kim SJ, Cho JY, Cho WY, et al. Therapeutic outcomes in 1000 cases of endoscopic submucosal dissection for early gastric neoplasms: Korean ESD Study Group multicenter study. Gastrointest Endosc. 2009;69:1228-35.

10. Hoteya S, Iizuka T, Kikuchi D, Yahagi N. Benefits of endoscopic submucosal dissection according to size and location of gastric neoplasm, compared with conventional mucosal resection. J Gastroenterol Hepatol. 2009;24:1102-6.

11. Chang CC, Lee IL, Chen PJ, Wang HP, Hou MC, Lee CT, et al. Endoscopic submucosal dissection for gastric epithelial tumors: a multicenter study in Taiwan. J Formos Med Assoc. 2009;108: 38-44.

12. Kikuchi D, Iizuka T, Hoteya S, Yamada A, Furuhata T, Yamashita S, Domon K, et al. Safety and efficacy of secondary endoscopic submucosal dissection for residual gastric carcinoma after primary endoscopic submucosal dissection. Digestion. 2012;86:288-93.

13. The Japanese Gastric Cancer Association. Japanese gastric cancer treatment guidelines 2010 (ver.3). Gastric Cancer. 2011;14: 113-23.

14. Japanese classification of gastric carcinoma: 3rd English edition. Gastric Cancer. 2011;14:101-2.

15. Yamamoto H, Kawata H, Sunada K, Sasaki A, Nakazawa K, Miyata T, et al. Successful en-bloc resection of large superficial tumors in the stomach and colon using sodium hyaluronate and small-caliber-tip transparent hood. Endoscopy. 2003;35:690-4.

16. Takenaka R, Kawahara Y, Okada H, Hori K, Inoue M, Kawano S, et al. Risk factors associated with local recurrence of early gastric cancers after endoscopic submucosal dissection. Gastrointest Endosc. 2008;68:887-94.

17. Oda I, Saito D, Tada M, Ishii H, Tanabe S, Oyama T, et al. A multicenter retrospective study of endoscopic resection for early gastric cancer. Gastric Cancer. 2006;9:262-70.

18. Oda I, Gotoda T, Sasako M, Sano T, Katai H, Fukagawa T, et al. Treatment strategy after non-curative endoscopic resection of early gastric cancer. Br J Surg. 2008;95:1495-500.

19. Goto O, Fujishiro M, Kodashima S, Ono S, Omata M. Outcomes of endoscopic submucosal dissection for early gastric cancer with special reference to validation for curability criteria. Endoscopy. 2009;41:118-22.
20. Isomoto H, Shikuwa S, Yamaguchi N, Fukuda E, Ikeda K, Nishiyama $\mathrm{H}$, et al. Endoscopic submucosal dissection for early gastric cancer: a large-scale feasibility study. Gut. 2009;58:331-6.

21. Jang JS, Choi SR, Qureshi W, Kim MC, Kim SJ, Jeung JS, et al. Long-term outcomes of endoscopic submucosal dissection in gastric neoplastic lesions at a single institution in South Korea. Scand J Gastroenterol. 2009;44:1315-22.

22. Lee H, Yun WK, Min BH, Lee JH, Rhee PL, Kim KM, et al. A feasibility study on the expanded indication for endoscopic submucosal dissection of early gastric cancer. Surg Endosc. 2011;25:1985-93.

23. Choi MK, Kim GH, Park do Y, Song GA, Kim DU, Ryu DY, et al. Long-term outcomes of endoscopic submucosal dissection for early gastric cancer: a single-center experience. Surg Endosc. 2013;27:4250-8.

24. Tanabe S, Ishido K, Higuchi K, Sasaki T, Katada C, Azuma M, et al. Long-term outcomes of endoscopic submucosal dissection for early gastric cancer: a retrospective comparison with conventional endoscopic resection in a single center. Gastric Cancer. 2013.

25. Tsuji Y, Ohata K, Ito T, Chiba H, Ohya T, Gunji T, et al. Risk factors for bleeding after endoscopic submucosal dissection for gastric lesions. World J Gastroenterol. 2010;16:2913-7.

26. Yoon H, Kim SG, Choi J, Im JP, Kim JS, Kim WH, et al. Risk factors of residual or recurrent tumor in patients with a tumorpositive resection margin after endoscopic resection of early gastric cancer. Surg Endosc. 2013;27:1561-8.

27. Bae SY, Jang TH, Min BH, Lee JH, Rhee PL, Rhee JC, et al. Early additional endoscopic submucosal dissection in patients with positive lateral resection margins after initial endoscopic submucosal dissection for early gastric cancer. Gastrointest Endosc. 2012;75:432-6.

28. Oka S, Tanaka S, Kaneko I, Mouri R, Hirata M, Kanao H, et al. Endoscopic submucosal dissection for residual/local recurrence of early gastric cancer after endoscopic mucosal resection. Endoscopy. 2006;38:996-1000.

29. Yokoi C, Gotoda T, Hamanaka H, Oda I. Endoscopic submucosal dissection allows curative resection of locally recurrent early gastric cancer after prior endoscopic mucosal resection. Gastrointest Endosc. 2006;64:212-8.

30. Higashimaya M, Oka S, Tanaka S, Numata N, Sanomura Y, Yoshida S, et al. Endoscopic submucosal dissection for residual early gastric cancer after endoscopic submucosal dissection. Gastrointest Endosc. 2012;77:298-302. 